\title{
PREVALENCE OF PREHYPERTENSION AND HYPERTENSION AND ITS CORRELATION WITH ANTHROPOMETRIC MEASUREMENTS IN MEDICAL STUDENTS OF CENTRAL INDIA
}

\author{
J. Jain ${ }^{1}$, H. Mathur², S. Apte ${ }^{3}$, U. Sinha ${ }^{4}$, K. Agarwal'5, R. Chanchlani ${ }^{6}$
}

\section{HOW TO CITE THIS ARTICLE:}

J. Jain, H. Mathur, S. Apte, U. Sinha, K. Agarwal, R. Chanchlani "Prevalence of Prehypertension and Hypertension and its Correlation with Anthropometric Measurements in Medical Students of Central India". Journal of Evolution of Medical and Dental Sciences 2014; Vol. 3, Issue 10, March 10; Page: 2429-2433,

DOI: $10.14260 /$ jemds/2014/2155

\begin{abstract}
BACKGROUND: Hypertension is a growing health problem in Asia, while most studies describe hypertension in older adults and elderly there is paucity of data on hypertension in teenagers and young adults. MATERIAL AND METHODS: A cross sectional study was conducted from Dec 2013 to Jan 2014 in Chirayu medical College and Hospital. A total of 300 students were included in the study those who volunteered for participation. Hypertension was diagnosed based on drug treatment for hypertension or if the blood pressure was greater than 140/90 $\mathrm{mmHg}$ - Joint National Committee 7 (JNC VII) Criteria. ${ }^{8}$ Anthropometric measurements including weight, height, waist and hip measurements were obtained using standardized techniques. RESULTS: Out of total 300 subjects $128(42.6 \%)$ were prehypertensives, 20 (6.66\%) had stage I hypertension and $04(1.3 \%)$ had stage II hypertension. Out of total 300 subjects 40 (13.3\%) subjects had BMI < 18.5, 168 (56\%) had BMI between 18.5 and 23.9, 38 (12.6\%) had BMI between 24- 26.9 and 54 (18\%) had BMI $\geq 27$. CONCLUSION: Overweight and obesity are a major health hazard all over the world and are becoming a major health threat among both the sexes and all age groups. Substantial proportions of young adult medical students are prehypertensives, overweight and obese. Our results highlight the necessity to institute effective prevention and health promotion programs targeting younger age groups.
\end{abstract}

KEYWORDS: BMI, Central Adiposity, Hypertension, Obesity, Overweight.

INTRODUCTION: Hypertension is a growing health problem in Asia. ${ }^{1}$ While most studies describe hypertension in older adults and elderly there is a paucity of data on hypertension in teenagers and young adults. Hypertension may be more common among young adults than previously thought, data from the National Study of adolescent Health (Add Health) indicate. ${ }^{2}$ There is a growing concern about this as the cases might not be detected because of inadequate screening. Obesity increases the risk of cardiovascular diseases in adults. ${ }^{3}$ The world health organization (WHO) has declared obesity as a disease of pandemic significance. ${ }^{4}$ Hypertension alone is among most prevalent risk factor of cardio \& cerebrovascular disease. ${ }^{5}$ In recent years, body mass index (BMI) has become the measurement of choice for many obesity researchers and health professionals to measure overweight \& obesity in adults. ${ }^{6}$ BMI describes relative weight for height, is not gender specific. The evaluation of central adiposity by way of the waist to hip ratio (WHR) has been recognized as a substantial component in the assessment of cardiovascular disease risk factors due to an association between WHR \& hypertension. ${ }^{7}$ The objective of present study was to measure the prevalence of hypertension in medical college students and find out any relationship of their blood pressure status with BMI, WC \& WHR. 
MATERIAL AND METHODS: A cross sectional study was conducted from Dec 2013 to Jan 2014 in Chirayu medical College and Hospital. A total of 300 students were included in the study those who volunteered for participation in the study. A predesigned and pretested questionnaire was filled by the students after the purpose of study was explained to them. Blood pressure was recorded in the sitting position in the right arm to the nearest $2 \mathrm{mmHg}$ using the mercury sphygmomanometer. Two readings were taken 15 minutes apart and mean of two was taken as the blood pressure. Hypertension was diagnosed based on drug treatment for hypertension or if the blood pressure was greater than 140/90 mmHg - Joint National Committee 7 (JNC VII) Criteria. ${ }^{8}$ Anthropometric measurements including weight, height, waist and hip measurements were obtained using standardized techniques. ${ }^{9,10}$ Height was measured with a tape to the nearest $\mathrm{cm}$. Subjects were requested to stand upright without shoes with their back against the wall, heels together and eyes directed forward. Weight was measured with a traditional spring balance that was kept on a firm horizontal surface. Subjects were asked to wear light clothing and weight was recorded to the nearest $0.5 \mathrm{~kg}$. Proforma were analyzed after excluding the incomplete ones. BMI was used as a measure of obesity and was derived by using the standard formula.

RESULTS: Out of total 300 subjects participated in the study 104() were male and 196() were female. Age range of the subjects was 17-26 years with a mean age of 19.57 years. Out of total 300 subjects $128(42.6 \%)$ were prehypertensives, 20 (6.66\%) had stage I hypertension and $04(1.3 \%)$ had stage II hypertension. (Table no. 1).

Out of total 300 subjects 40 (13.3\%) subjects had BMI < 18.5, 168 (56\%) had BMI between 18.5-23.9, 38 (12.6\%) had BMI between 24-26.9 and 54 (18\%) had BMI $\geq 27$. (Table no. 2).

Out of total 300 subjects $38(12.6 \%)$ were alcohol consumers. The association of hypertension with alcohol consumption and non-consumption is significant (P value 0.0037). Out of total 300 subjects $10(3.3 \%)$ were smokers. The association of hypertension with smoking and nonsmoking is significant (P value 0.0001$)$. Out of total 300 subjects $40(13.3 \%)$ subjects had BMI < 18.5, 168(56\%) had BMI between 18.5-23.9, 38 (12.6\%) had BMI between 24-26.9 and 54 (18\%) had $\mathrm{BMI} \geq 27$. The association of hypertension with obesity is significant (P value 0.0001 ). Out of total 104 males 36(34.6\%) had WC more than $90 \mathrm{~cm}$ and out of total 196 females 144(73.46\%) had WC more than $80 \mathrm{~cm}$. The association of hypertension with WC is significant (P value 0.0001$)$. Out of total 104 males 52(50\%) had WHR >.9 and out of total 196 females 108(55.1\%) had WHR >.85. The association of hypertension with WHR is not significant (P value 0.3147) (Table no. 3).

DISCUSSION: The present study found that the proportion of prehypertension and hypertension in college students were $41.3 \%$ and $7.9 \%$ respectively. These results were similar to the study done by Al-Majed HT, Sadek AA in Kuwait. ${ }^{11}$ In present study the prevalence of hypertension in males and females were $3.9 \%$ in both and the prevalence of prehypertension in males and females were $18.6 \%$ and $22.6 \%$, whereas in other studies prevalence of both prehypertension and hypertension was found more in males than females. ${ }^{12,13}$

Regarding the smoking habit, the percentage of students who smoked in relation to the status of blood pressure, that is, hypertension was found in $40 \%$ of the subjects who were smokers in comparison to $7.5 \%$ those who were non-smokers (P value). Whereas in an another study done by Makwana N, Shah V, Khambhati S, Choudhary M, Goswami K, Yadav S, hypertension was found in 
$28.21 \%$ of the subjects who were smokers in comparison to $4.74 \%$ those who were non-smokers (P value 0.8379$).{ }^{14}$

In present study out of total 300 subjects $38(12.66 \%)$ were found overweight in which females outnumbered twice than males. Similarly out of total 300 subjects 54 (18\%) were found obese with m: $\mathrm{f}$ ratio of 20:34. Whereas in another study done by Shamail Zafar et al in Pakistan, out of total 483 medical students 99 (20.5\%)of subjects were found as overweight and $30(6.2 \%)$ as obese. ${ }^{15}$

In present study out of total 300 subjects $180(60 \%)$ had central obesity as defined by WC cut off values for men $>90 \mathrm{~cm}$ and women $>80 \mathrm{~cm}$. Out of these 180 subjects $36(12 \%)$ were males and 144(48\%) were females. Whereas in another study done by Shamail Zafar et al in Pakistan, out of total 483 medical students abdominal adiposity was present in 56 subjects $(11.59 \%)$ with males more obese than females, almost similar findings were there in a study from Iran which showed prevalence to be around $11.4 \% .{ }^{15,16}$

Significant number of study participants had central adiposity as defined by WHR (60\%). Prevalence being more in female subjects (65.3\%). Whereas in another study done by Renulohitashwa and Parvati Patil et.al in 2013 showed overall WHR (73.3\%) and prevalence being more in female subjects $(84.3 \%){ }^{17}$

CONCLUSION: Overweight and obesity are a major health hazard all over the world and are becoming a major health threat among both the sexes and all age groups. Substantial proportions of young adult medical students are prehypertensives, overweight and obese. Our results highlight the necessity to institute effective prevention and health promotion programs targeting younger age groups. In view of the fact that medical students are not representative of the general population, studies should be extended to the young adult population and investigate the presence of obesity and major CVD risk factors and their trends over time.

\section{REFERENCES:}

1. The Guideline Subcommittee of the World Health Organisation International society of Hypertension (WHO_ISM) mild hypertension Liasion committee; 1999m. J. Hypertension: 17:151-83.

2. Nguyen QC. Rexrode KM, Manson JE, Hennekens CH. Obesity and cardiovascular Epidemiology. 2011; 22: 532-541.

3. Rexrode KM, Manson JE, Hennekens CH. Obesity and cardiovascular disease. Curr Opin Cardiol. 1996; 11: 490-495.

4. World Health organisation. Obesity epidemic puts millions at risk from related diseases. Edition 12, 1997. Available from URL; http//www.who.int/inf-prp 1997/en/pr 97-46.

5. Sidell JC, Cigolini m, Charzewska J. Fat distribution in European women: A comparison of anthropometric measurements in relation to cardiovascular disease risk factor. Int J Epidemiol 1990; 17:197-203.

6. Brown CD, Higgins M, Donato KA. Body mass index and the prevalence of hypertension and dyslipidemia. Obes Res 2000; 8: 605-19.

7. McKeigue PM, Shah B, Marmot MG. Relation of central obesity and insulin resistance with high diabetes prevalence and cardiovascular risk in south Asians. Lancet1991;337:382-6 
8. Chobanian AV, Bakris GL, Black HR, Cushman WC, Green LA, Izzo JL, et al. The seventh report of the Joint National Committee on Prevention, Detection, Evaluation and Treatment of High Blood Pressure (JNC-7). JAMA 2003; 289: 2560-71.

9. Wildman RP et al. Appropriate body mass index and waist circumference cut offs for categorization of overweight and central adiposity among Chinese adults. American Journal of Clinical Nutrition 2004; 80:1129.

10. Appropriate body-mass index for Asian populations and its implications for policy and intervention strategies. Lancet 2004; 363:157-63.

11. Al-Majed HT, Sadek AA. Pre-hypertension and hypertension in college students in Kuwait: a neglected issue. J Family Community Med. 2012 May; 19 (2):105-12.

12. Erem C, Hacihasanoglu A, Kocak M, Deger 0, Topbas M. Prevalence of prehypertension and hypertension and associated risk factors among Turkish adults: Trabzon Hypertension Study. J Public Health (Oxf) 2009;31:47-58

13. Oladapo 00, Salako L, Sodig O, Shoyinka K, Adedapo K, Falase AO. A prevalence of cardiometabolic risk factors among a rural Yoruba south-western Nigerian population: A population-based survey. Cardiovasc J Afr 2010; 21:26-31.

14. Makwana N, Shah V, Khambhati S, Choudhary M, Goswami K, Yadav S. Assessment of risk factors of Hypertension: a cross-sectional study. JEMDS October 2012.

15. Zafar S, Haque S, Rasheed A, Mirza H. Relationship of body mass index and waist to hip ratio measurement with hypertension in young adult medical student. Pak j med sci July - September 2007 vol. 23 no. 4 574-579.

16. Shahbazpour N. Prevalence of Overweight and Obesity and Their Relation to Hypertension in Adult Male University Students in Kerman, Iran. Int J Endocrinol Metab 2003; 2:55-60.

17. lohitashwa R, Patil P. Prevalence and trends of obesity and hypertension among young adult medical students. A cross sectional study. Int J Biol Med Res 2013; 4(4):3540-3543.

\begin{tabular}{|c|c|c|c|}
\hline Hypertension & $\begin{array}{c}\text { Males } \\
\mathbf{n}(\%)\end{array}$ & $\begin{array}{c}\text { Females } \\
\mathbf{n}(\%)\end{array}$ & $\begin{array}{c}\text { Total } \\
\mathbf{n}(\%)\end{array}$ \\
\hline Normal & $36(12)$ & $116(38.6)$ & $152(50.6)$ \\
\hline Pre HTN & $56(18.6)$ & $68(22.6)$ & $124(41.3)$ \\
\hline Stage I & $08(2.6)$ & $12(3.9)$ & $20(6.6)$ \\
\hline Stage II & $04(1.3)$ & $00(00)$ & $04(1.3)$ \\
\hline Total & $\mathbf{1 0 4 ( 3 4 . 6 )}$ & $\mathbf{1 9 6}(\mathbf{6 5 . 3 )}$ & $\mathbf{3 0 0 ( 1 0 0 )}$ \\
\hline
\end{tabular}

Table no. 1: Distribution of the subjects according to the JNC 7 classification

\begin{tabular}{|c|c|c|c|}
\hline BMI & $\begin{array}{c}\text { Males } \\
\mathbf{n}(\%)\end{array}$ & $\begin{array}{c}\text { Females } \\
\mathbf{n}(\mathbf{\%})\end{array}$ & $\begin{array}{c}\text { Total } \\
\mathbf{n}(\mathbf{\%})\end{array}$ \\
\hline$<18.5$ & $10(3.33)$ & $30(10.0)$ & $40(13.3)$ \\
\hline $18.5-23.9$ & $60(20.0)$ & $108(36.0)$ & $168(56.0)$ \\
\hline $24-26.9$ & $14(4.66)$ & $24(8.0)$ & $38(12.66)$ \\
\hline$\geq 27$ & $20(6.66)$ & $34(11.33)$ & $54(18.0)$ \\
\hline Total & $\mathbf{1 0 4 ( 3 4 . 6 )}$ & $\mathbf{1 9 6}(\mathbf{6 5 . 3})$ & $\mathbf{3 0 0}(\mathbf{1 0 0})$ \\
\hline
\end{tabular}

Table no. 2: Distribution of the subjects according to the BMI 


\begin{tabular}{|c|c|c|c|c|c|}
\hline \multirow{2}{*}{ Risk Factor } & \multirow{2}{*}{ Number of Subjects } & \multicolumn{2}{|c|}{ Hypertension } & \multirow{2}{*}{$\begin{array}{c}\text { Chi square } \\
\text { value }\end{array}$} & \multirow{2}{*}{$\begin{array}{c}\mathbf{P} \\
\text { value }\end{array}$} \\
\hline & & Yes & No & & \\
\hline Alcohol consumption (yes) & 38 & 08 & 30 & \multirow[b]{2}{*}{8.433} & \multirow[b]{2}{*}{0.0037} \\
\hline (No) & 262 & 18 & 244 & & \\
\hline Smoking (yes) & 10 & 04 & 06 & \multirow[b]{2}{*}{15.96} & \multirow[b]{2}{*}{0.0001} \\
\hline (No) & 290 & 22 & 268 & & \\
\hline Obesity (BMI <18.5-23.9) & 208 & 04 & 204 & \multirow{3}{*}{67.01} & \multirow{3}{*}{0.0001} \\
\hline (BMI $24-26.9)$ & 38 & 2 & 36 & & \\
\hline$(\mathrm{BMI} \geq 27)$ & 54 & 20 & 34 & & \\
\hline WC (> cut off value) & 180 & 20 & 160 & \multirow[b]{2}{*}{16.01} & \multirow[b]{2}{*}{0.0001} \\
\hline$(<$ cut off value $)$ & 120 & 06 & 114 & & \\
\hline WHR (> cut off value) & 180 & 18 & 162 & \multirow[b]{2}{*}{1.011} & \multirow[b]{2}{*}{.3147} \\
\hline (< cut off value $)$ & 120 & 08 & 112 & & \\
\hline
\end{tabular}

\section{AUTHORS:}

1. J. Jain

2. H. Mathur

3. S. Apte

4. U. Sinha

5. K. Agarwal

6. R. Chanchlani

\section{PARTICULARS OF CONTRIBUTORS:}

1. Associate Professor, Department of Medicine, Chirayu Medical College and Hospital, Bhopal.

2. Assistant Professor, Department of Medicine, Chirayu Medical College and Hospital, Bhopal.

3. Associate Professor, Department of Medicine, Chirayu Medical College and Hospital, Bhopal.

4. Associate Professor, Department of Community Medicine, Chirayu Medical College and Hospital, Bhopal.
5. 2n $\quad 2^{\text {nd }}$ Year Medical Student, Department of Medicine, Chirayu Medical College and Hospital, Bhopal.

6. Associate Professor, Department of Surgery, Chirayu Medical College and Hospital, Bhopal.

\section{NAME ADDRESS EMAIL ID OF THE} CORRESPONDING AUTHOR:

Dr. Roshan Chanchlani,

1/6 - Idgah Kothi,

Doctors Enclave,

Near Filter Plant,

Idgah Hills, Bhopal - 462001, M. P.

E-mail: roshanchanchlani@gmail.com

Date of Submission: 13/02/2014.

Date of Peer Review: 14/02/2014.

Date of Acceptance: 18/02/2014.

Date of Publishing: 04/03/2014. 